\title{
In-Situ Observation of Composition Profiles in the Solution \\ by X-ray Penetration Method
}

Yasuhiro Hayakawa $^{1 *}$, Takuya Hikida ${ }^{1)}$, Hisashi Morii ${ }^{1)}$, Akiko Konno ${ }^{1)}$, Chung-Hao Chen $^{1)}$, Kouji Arafune ${ }^{1)}$, Hideki Kawai ${ }^{1)}$, Tadanobu Koyama ${ }^{1)}$, Yoshimi Momose ${ }^{1)}$, Tetsuo Ozawa ${ }^{2)}$ and Toru Aoki ${ }^{1)}$

${ }^{1)}$ Research Institute of Electronics, Shizuoka University, Johoku 3-5-1, Naka-ku, Hamamatsu, Shizuoka 432-8011, Japan

${ }^{2)}$ Department of Electrical Engineering, Shizuoka Institute of Science and Technology, Fukuroi, Shizuoka 437-8555, Japan, royhaya@ipc.shizuoka.ac.jp

Keywords: $\mathrm{X}$-ray penetration, concentration profile, $\mathrm{NH}_{4} \mathrm{Br}$ solution, $\mathrm{InGaSb}$,

PACS codes: $\quad$ 78.70.Ck, 81.10.-h, 81.10Dn, 8.10Mx
Keywords:
A1. Mass transfer
A2. Growth from solution
B1. Gallium compounds
B2. Semiconducting III-V materials

Corresponding author; TEL: +81-53-478-1310, FAX: +81-53-478-1310,

E-mail address: royhaya@ipc.shizuoka.ac.jp (Y.Hayakawa) 


\begin{abstract}
The X-ray penetration intensity during the diffusion process of $\mathrm{NH}_{4} \mathrm{Br}$ into $\mathrm{H}_{2} \mathrm{O}$ was measured by a CdTe line sensor as a function of time and it was converted to the $\mathrm{NH}_{4} \mathrm{Br}$ composition using a calibration line. The diffusion coefficient of $\mathrm{NH}_{4} \mathrm{Br}$ into $\mathrm{H}_{2} \mathrm{O}$ was estimated to be $2.2 \times 10^{-5} \mathrm{~cm}^{2} / \mathrm{s}$ by comparing the calculated results. The method was applied to the growth of InGaSb from the In-Ga-Sb solution. The indium composition profiles in the solution were measured and growth of InGaSb from the In-Ga-Sb solution was observed from change of X-ray intensity. The growth region of InGaSb crystal was confirmed by the electron probe micro analysis. It was demonstrated that the X-ray penetration method was a powerful method to measure the composition profiles in the solution.
\end{abstract}

\title{
1. Introduction
}

Ternary alloy semiconductor crystals are important materials for opto-electronic devices because fundamental properties such as lattice constant and band gap can be controlled by adjusting composition ratio. The alloy crystals offer the possibility to reduce the problem of lattice mismatch at the interface between a substrate and an epilayer. Ternary alloy crystals such as InGaAs [1-7], InGaSb [8-12], InSbBi [13-14], InAsSb [15-16] have been grown until now. However, it is very difficult to grow large single crystals of high quality, because there are three major problems which must be overcome. The first is the constitutional supercooling which brings about the instability at the growth interface [17]. The second is the change of composition profiles both in the crystal and in the solution during growth. Since the segregation coefficient of each component is not unity, the composition ratio in the 
alloy crystal continues to change. The third relates to the flows caused by heat and mass transfer. The quality of alloy crystals is strongly affected by the flow patterns.

We have grown homogeneous InGaSb crystals by the temperature cooling method under a constant temperature gradient using a $\mathrm{GaSb}$ (seed)/Te-doped $\mathrm{InSb} / \mathrm{GaSb}$ (feed) sandwich structure [18]. At $600^{\circ} \mathrm{C}$, an InSb crystal is completely melted since the melting temperature of $\mathrm{InSb}$ is $525^{\circ} \mathrm{C}$. GaSb seed crystal and $\mathrm{GaSb}$ feed crystal partially dissolve into In-Sb melt and In-Ga-Sb solution is formed. The temperature at solution/feed interface is higher than that seed/solution interface, which results $\mathrm{GaSb}$ composition at solution/feed interface higher than that of seed/solution interface. Therefore, the GaSb moves to the seed/solution interface by diffusion and convection due to GaSb composition gradient between solution/feed and seed/solution interface. The solution near the seed/solution interface becomes supersaturated, which cause spontaneous $\operatorname{In}_{\mathrm{x}} \mathrm{Ga}_{1-\mathrm{x}} \mathrm{Sb}$ crystal growth at seed/solution interface without moving the ampoule. Since the segregation coefficient of $\mathrm{GaSb}$ is larger than unity, the larger amount of $\mathrm{GaSb}$ component is incorporated in the $\mathrm{In}_{\mathrm{x}} \mathrm{Ga}_{1-\mathrm{x}} \mathrm{Sb}$ crystal. As a result, $\mathrm{GaSb}$ component in the solution is deficient during growth. GaSb component should be supplied during growth to grow homogeneous $\operatorname{In}_{\mathrm{x}} \mathrm{Ga}_{1-\mathrm{x}} \mathrm{Sb}$. To grow homogeneous crystals, the balance among the dissolution rate of feed, growth rate of crystal and the transportation of solute in the solution is very important. Since the degree of constitutional supercooling also relates to the composition profile in the solution, the development of the in-situ measurement technique of the composition profile in the solution during growth is strongly required.

Interferometry technique using a laser is a very useful method to investigate the composition profile near the growth interface in the solution [19-20]. However, it is 
very difficult to measure the composition profile in the metallic solution since the light can not penetrate into it. On the other hand, Kakimoto et al. measured solid-liquid interface shape by X-ray radiography method during crystal growth of Si since X-ray can penetrate into Si melt [21].

We have developed the X-ray penetration method using a CdTe line sensor to investigate the composition profile in the solution. At first, the diffusion experiment of $\mathrm{NH}_{4} \mathrm{Br}$ into $\mathrm{H}_{2} \mathrm{O}$ was carried out to investigate the validity of the X-ray penetration method. The composition profile was detected as a function of time and the profile was compared with the calculated profile. Since the both results agreed well, the X-ray penetration method was adapted to investigate the composition profile in the In-Ga-Sb solution during growth.

\section{Experimental method}

Fig. 1 shows a configuration of the measurement system. The sample was set up on the platform, which could move along $\mathrm{X}, \mathrm{Y}$ and $\mathrm{Z}$ axis and could rotate 360 degree. X-ray source is a tungsten target with an acceleration voltage of $150 \mathrm{kV}$. The detector is a CdTe line sensor composed of 64 segments. The shape of a segment is rectangle, and the width is $2 \mathrm{~mm}$ and the height is $1 \mathrm{~mm}$. So, total height of the sensor is $64 \mathrm{~mm}$. The diffusion process of $\mathrm{NH}_{4} \mathrm{Br}$ into $\mathrm{H}_{2} \mathrm{O}$ was in-situ measured at $20^{\circ} \mathrm{C}$ by the X-ray penetration method with an X-ray current of $31 \mu \mathrm{A}$. In order to get a relationship between the X-ray penetration intensity and the $\mathrm{NH}_{4} \mathrm{Br}$ composition in $\mathrm{H}_{2} \mathrm{O}$, nine samples with different $\mathrm{NH}_{4} \mathrm{Br}$ composition of $0,5,10,15,20,25,30,35,40$ wt\% were prepared. The X-ray penetration intensity of the samples was transformed into absorbance and the calibration line between absorbance and $\mathrm{NH}_{4} \mathrm{Br}$ composition 
was fabricated.

Fig. 2 shows the configuration of the sample. Initially, $\mathrm{NH}_{4} \mathrm{Br}$ solution with 40 wt.\% composition and $\mathrm{H}_{2} \mathrm{O}$ were separately inserted into the glass boxes. The lengths of the $\mathrm{NH}_{4} \mathrm{Br}$ solution and $\mathrm{H}_{2} \mathrm{O}$ were $1 \mathrm{~cm}$ and $1 \mathrm{~cm}$, respectively. They were divided into two parts by a sheet to establish initial condition. Since the density of $\mathrm{NH}_{4} \mathrm{Br}$ is $2.429 \mathrm{~g} / \mathrm{cm}^{3}$ and it is larger than that of $\mathrm{H}_{2} \mathrm{O}, \mathrm{NH}_{4} \mathrm{Br}$ solution was set under $\mathrm{H}_{2} \mathrm{O}$. In order to make clear the position of the sample, lead $(\mathrm{Pb})$ plates were placed at the top and the bottom area of the sample. Since the X-ray did not penetrate the $\mathrm{Pb}$ plate, the edge of the sample was distinguished. The mixing of the solution was started by removing the sheet. After $3 \mathrm{~min}$, the X-ray penetration intensity was measured continuously as a function of time and it was converted to the $\mathrm{NH}_{4} \mathrm{Br}$ composition using the calibration line. The absorbance values of the $\mathrm{Pb}$ plate and air were divided into 1275 scales and displayed in color. The composition profiles were calculated by solving the diffusion equations by finite difference method and compared with the experimental results.

This method was applied to measure the profile of indium composition in the In-Ga-Sb solution during growth of $\mathrm{InGaSb}$ on a $\mathrm{GaSb}$ seed. Fig. 3 shows the configuration of the sample and the temperature profile. GaSb and InSb crystals were processed into cylindrical shape and the GaSb(seed) - InSb - GaSb(feed) sandwich sample was prepared. The respective lengths of the $\mathrm{GaSb}$ and $\mathrm{InSb}$ were $0.8 \mathrm{~cm}$ and $0.4 \mathrm{~cm}$. The $\mathrm{GaSb} / \mathrm{InSb} / \mathrm{GaSb}$ sandwich sample with the diameter of $2 \mathrm{~mm}$ was taken in a $\mathrm{BN}$ tube, and then inserted into a quartz tube. It was evacuated to about $10^{-4} \mathrm{~Pa}$ and sealed. We have measured the temperature gradient in the furnace by using the thermocouples before experiment, but could not measure the temperature gradient in 
the sample since the sample was inserted in the quartz. The temperature gradient of the furnace was $1.3^{\circ} \mathrm{C} / \mathrm{mm}$. The temperature was monitored by the thermocouple positioned outside the ampoule.

The sample was vertically set up in the furnace. The X-ray penetration intensity of the sample was measured by moving the sample along the $\mathrm{Y}$ axis. Since the sample was cylindrical, the $\mathrm{X}$ ray penetration intensity from the center of the sample had the smallest value. We fixed the sample at the place where the X-ray intensity was the smallest. The X-ray image of the sample was displayed on the screen. So, we could check the sample was inclined or not. The distance between the X-ray source and sensor was also adjusted to match the sample shadow by moving the sensor to the $\mathrm{X}$ direction. The distance between the $\mathrm{X}$ ray source and the sample was $320 \mathrm{~mm}$ and that between the $X$ ray source and the sensor was $952 \mathrm{~mm}$. The image of the sample was magnified about 3 times on the sensor. Since the size of a segment of the sensor was 1 $\mathrm{mm}$, the resolution of the sensor was about $0.33 \mathrm{~mm}$.

The acceleration voltage was $150 \mathrm{kV}$ and current was $1 \mathrm{~mA}$. In order to get a relationship between the X-ray penetration intensity and $\operatorname{In}_{\mathrm{x}} \mathrm{Ga}_{1-\mathrm{x}} \mathrm{Sb}$ composition, the $\mathrm{X}$-ray penetration intensities of $\mathrm{GaSb}$ and $\mathrm{InSb}$ solids were measured. They were transformed into absorbance. The calibration line between absorbance and $\operatorname{In}_{\mathrm{x}} \mathrm{Ga}_{1-\mathrm{x}} \mathrm{Sb}$ composition was determined.

The temperature of the furnace increased to $600^{\circ} \mathrm{C}$ and then kept constant. After that, the sample was loaded into the furnace. The InSb crystal was completely melted and 2 solid-liquid interfaces were established. The X-ray intensity of the sample was measured as a function of time. The measurement was carried out for $5 \mathrm{~h}$ by keeping the reference temperature constant. After that, the sample was quenched by 
turning off the power of the heater.

After the X-ray penetration experiment, the sample was cut parallel to the growth axis and the surface was polished with an abrasive of $5 \mu \mathrm{m}$. The indium composition profile was measured by the Electron probe micro analysis (EPMA). The EPMA measurement was carried out at every $10 \mu \mathrm{m}$ near the growth area.

\section{Result and discussion}

\section{1 $\mathrm{NH}_{4} \mathrm{Br}$ composition profiles in $\mathrm{H}_{2} \mathrm{O}$}

Fig. 4 shows the $\mathrm{NH}_{4} \mathrm{Br}$ composition profiles as a function of time. The composition profiles were displayed with color scale. The measurement was carried out every $0.2 \mathrm{sec}$ and the one figure includes the data of $1 \mathrm{~min}$. The red color indicates that the X-ray intensity could not be measured due to a flaw of CdTe cell. The black area and green area at the top and bottom region indicates the positions of $\mathrm{Pb}$ plate and quartz box, respectively. $\mathrm{Pb}$ plates were fixed on the top and bottom of the quartz box using an adhesive tape. The $\mathrm{X}$ ray penetration intensity of the adhesive tapes was stronger than that of the quartz. Therefore, the area of adhesive tapes appears yellowish color between $\mathrm{Pb}$ and quartz. The yellow and blue color indicates $\mathrm{H}_{2} \mathrm{O}$ and $\mathrm{NH}_{4} \mathrm{Br}$ solution, respectively. The green color between the yellow and blue shows the mixing of $\mathrm{H}_{2} \mathrm{O}$ and $\mathrm{NH}_{4} \mathrm{Br}$ solution. As the time was passed, the green area increased. It indicated that diffusion of $\mathrm{NH}_{4} \mathrm{Br}$ into $\mathrm{H}_{2} \mathrm{O}$ was proceeded.

Fig. 5 shows the $\mathrm{NH}_{4} \mathrm{Br}$ composition profiles as a function of time. The $\mathrm{X}$ axis indicates the distance from the bottom of $40 \% \mathrm{NH}_{4} \mathrm{Br}$ solution. The initial position of the $\mathrm{NH}_{4} \mathrm{Br}$ solution and $\mathrm{H}_{2} \mathrm{O}$ was located at $1 \mathrm{~cm}$. Open triangles, closed triangles, open circles and closed circles indicate the profiles at 3, 20, 40 and $60 \mathrm{~min}$ 
after the measurement, respectively. It is clearly shown that $\mathrm{NH}_{4} \mathrm{Br}$ composition was gradually decreased from the left side to the right side with time.

The composition profiles were calculated by solving the diffusion equations using finite difference method. The composition profile was calculated by assuming the value of the diffusion coefficient and compared with the experimental results. The procedure was repeated by changing the diffusion coefficient till the calculated profile fit the experimental result. Fig. 6 shows the profiles at $60 \mathrm{~min}$. A dotted line, a solid line and a broken line indicate the profiles calculated using the diffusion coefficient of $1.6 \mathrm{x}$ $10^{-5} \mathrm{~cm}^{2} / \mathrm{s}, 2.2 \times 10^{-5} \mathrm{~cm}^{2} / \mathrm{s}$ and $3.0 \times 10^{-5} \mathrm{~cm}^{2} / \mathrm{s}$, respectively. The diffusion coefficient of $\mathrm{NH}_{4} \mathrm{Br}$ solution into $\mathrm{H}_{2} \mathrm{O}$ was estimated to be $2.2 \times 10^{-5} \mathrm{~cm}^{2} / \mathrm{s}$. There is a small discrepancy between the experimental result and the calculated result. Capillary effect and convection due to the opening of the gate may affect the composition profile.

\subsection{Indium composition profiles of the $\mathrm{GaSb} / \mathrm{InSb} / \mathrm{GaSb}$ sandwich sample}

Fig. 7 indicates the indium composition profiles of the $\mathrm{GaSb} / \mathrm{InSb} / \mathrm{GaSb}$ sandwich sample measured by X-ray penetration method. The circular, rectangular and triangular points show the indium composition profiles at 1,3 and $5 \mathrm{~h}$ after loading the sample in the furnace, respectively. The GaSb seed and feed crystals were placed between the distance from 0 to $0.8 \mathrm{~cm}$ and from $1.2 \mathrm{~cm}$ to $1.8 \mathrm{~cm}$, and the $\mathrm{InSb}$ was placed from $0.8 \mathrm{~cm}$ to $1.2 \mathrm{~cm}$ at the initial stage. Since the melting temperature of $\mathrm{InSb}$ was $525^{\circ} \mathrm{C}$, an $\mathrm{InSb}$ crystal was completely melted at $600^{\circ} \mathrm{C}$. Since the respective densities of liquid InSb and solid InSb were $6320 \mathrm{~kg} / \mathrm{m}^{3}$ and $5780 \mathrm{~kg} / \mathrm{m}^{3}$, the volume of the InSb decreased about $9 \%$ by changing from solid to liquid. Since the GaSb feed was partially dissolved in the InSb melt, the position of the GaSb feed was shifted from 
$1.2 \mathrm{~cm}$ to $1.1 \mathrm{~cm}$. The length of the GaSb seed was also decreased from $0.8 \mathrm{~cm}$ to 0.64 $\mathrm{cm}$ by dissolving into the InSb melt. The indium composition ranged from 0.4 to 0.6 at the middle region between the GaSb seed and $\mathrm{In}-\mathrm{Ga}-\mathrm{Sb}$ solution. The region corresponded to the InGaSb crystal grown on the GaSb seed. The value of the indium composition in the In-Ga-Sb solution near the InGaSb crystal was larger than that near the $\mathrm{GaSb}$ feed. It was because the temperature of the GaSb feed was higher than that of the GaSb seed. Since larger amount of GaSb feed could dissolve into the solution, the indium composition decreased. The indium composition in the solution was increased as the time passed from $1 \mathrm{~h}$ to $5 \mathrm{~h}$. It was because the segregation coefficient of indium is less than unity. Since the indium composition in the crystal was smaller than that of the solution, the indium was accumulated in the solution with time.

The indium composition profile measured by EPMA after the X-ray penetration experiment was shown in fig. 8. It was found that InGaSb crystal was grown near the GaSb seed and the value of the indium composition was about 0.3. It corresponded to the solidified temperature of about $588^{\circ} \mathrm{C}$. The Indium composition gradually increased from 0.3 to 0.9 . It indicated the InGaSb was grown by decreasing the temperature and finally residual solution with the high indium composition was solidified. The indium composition measured by the X-ray penetration method ranged from 0.4 to 0.6 at the distance between $0.65 \mathrm{~cm}$ and $0.7 \mathrm{~cm}$ as shown in Fig.7. The date points were only 2 points. It was because the resolution of the sensor was about $0.33 \mathrm{~mm}$. We estimated the region to be $\mathrm{InGaSb}$ grown area by comparing the profile measured by EPMA.

\section{Conclusion}


Diffusion process of $\mathrm{NH}_{4} \mathrm{Br}$ into $\mathrm{H}_{2} \mathrm{O}$ was in-situ measured by the X-ray penetration method using a CdTe line sensor. A calibration line was established by measuring the relationship between the X-ray penetration intensity and the $\mathrm{NH}_{4} \mathrm{Br}$ composition in $\mathrm{H}_{2} \mathrm{O}$. The diffusion coefficient of $\mathrm{NH}_{4} \mathrm{Br}$ into $\mathrm{H}_{2} \mathrm{O}$ was estimated to be $2.2 \times 10^{-5} \mathrm{~cm}^{2} / \mathrm{s}$ by comparing the calculated composition profiles with the experimental results. The method was applied to the growth of InGaSb from the In-Ga-Sb solution. The GaSb/InSb/GaSb sandwich sample with the diameter of $2 \mathrm{~mm}$ was heated to $600^{\circ} \mathrm{C}$ under a temperature gradient of $1.3^{\circ} \mathrm{C} / \mathrm{mm}$. The Indium composition profiles in the solution and of the InGaSb grown crystal were measured as a function of time. The growth region of InGaSb crystal was confirmed by the electron probe micro analysis. It was demonstrated that the X-ray penetration method was a powerful method to measure the composition profiles in the solution.

\section{References}

[1] K. Nakajima and T. Kusunoki, J. Crystal Growth 169 (1996) 217.

[2] Y. Nishijima, K. Nakajima, K. Otsubo and H. Ishikawa, J.Crystal Growth 208 (2000) 171.

[3] K. Hashio, M. Tatsumi, H. Kato and K. Kinosita, J.Crystal Growth 210 (2000) 471.

[4] Y. Hayakawa, T. Ozawa, M . Ando, T. Koyama, M. Masaki, K. Takahashi and M. Kumagawa, Cryst.Res.Technol. 31 [5], (1996) 567.

[5] T. Ozawa, Y. Hayakawa, K. Balakrishnan, F. Ohonishi, T. Koyama and M. Kumagawa, J.Crystal Growth 229 (2001) 124.

[6] Y. Hayakawa, T. Ozawa, T. Araki, M. Haris and M. Kumagawa, J.Crystal 
Growth 275 [1-2] (2005) e421.

[7] Y. Hayakawa, T. Ozawa, M. Haris and M. Kumagawa, New Research on Semiconductors, Ed T.B.Elliot (Nova Science, USA, 2006) 1.

[8] T. Tsuruta, Y. Hayakawa and M. Kumagawa, Jpn.J.Appl.Phys., 27, suppl.27-1, (1988) 47.

[9] J.P. Garandet, T. Duffar and J.J. Favier, J. Crystal Growth 106 (1990) 426.

[10] A. Watanabe, A. Tanaka and T. Sukegawa, Jpn.J.Appl.Phys. 32 (1993) L793.

[11] A. Tanaka, T. Yoneyama, M. Kimura and T. Sukegawa, J. Crystal Growth 186 (1998) 305.

[12] Y. Hayakawa, K. Balakrishnan, H. Ohtsu, T. Koyama and M. Kumagawa, Jpn.J.Appl.Phys., 42 (2003) 44.

[13] M. Kumagawa, T. Ozawa and Y. Hayakawa, Appl.Surf.Science, 33/34 (1988) 611.

[14] T. Ozawa, Y. Hayakawa and M. Kumagawa, J.Crystal Growth 109 (1991) 212.

[15] M. Haris, P. Veeramani, P. Jayavel, Y. Hayakawa and S.M. Babu, Mater Manuf Process 22 (2007) 404.

[16] V.K. Dixit, B. Bansal, V. Venkataraman, and H.L. Bhat, Appl. Phys. Lett. 81 [9] (2002) 1630.

[17] K.M. Kim, J. Crystal Growth 44 (1978) 403.

[18] N. Murakami, K. Arafune, T. Koyama, M. Kumagawa and Y. Hayakawa, J.Crystal Growth 275 (2005) 433.

[19] K. Tsukamoto, Morphology and Growth Unit of Crystals, Ed. I.Sunagawa (Terra Scientific Publishing Company, 1989) 45.

[20] K. Tsukamoto, E. Yokoyama, S. Maruyama, K. Maiwa, K. Shimizu, R.F. Sekerka, 
T.S. Morita and S. Yoda, J.Jpn.Soc.Microgravity Appl. 15 (1998) 2.

[21] K. Kakimoto, M. Eguchi, H. Watanabe and T. Hibiya, J. Crystal Growth 91 (1988) 509.

\section{Figure captions}

Fig. 1. Configuration of the measurement system. X-ray source with a tungsten target with an applied voltage of $150 \mathrm{kV}$ and a CdTe line sensor were used.

Fig. 2. Configuration of the sample. Initially, $\mathrm{NH}_{4} \mathrm{Br}$ solution and $\mathrm{H}_{2} \mathrm{O}$ were separately inserted into the glass boxes. The mixing of the solution was started by removing a sheet between $\mathrm{NH}_{4} \mathrm{Br}$ solution and $\mathrm{H}_{2} \mathrm{O}$.

Fig. 3. Configuration of the sample. (a) temperature profile, (b) ampoule configuration and (c) outside view of the ampoule.

Fig. 4. $\mathrm{NH}_{4} \mathrm{Br}$ composition profiles as a function of time. The composition profiles were displayed with color scale. The $\mathrm{x}$-axis indicates the time lapse.

Fig. 5. $\mathrm{NH}_{4} \mathrm{Br}$ concentration profiles as a function of time. The $\mathrm{x}$ axis indicates the distance from the bottom of $40 \% \mathrm{NH}_{4} \mathrm{Br}$ solution.

Fig. 6. The solid circles indicate the experimental data at $60 \mathrm{~min}$. A dotted line, a solid line and a broken line indicate the profiles calculated using the diffusion coefficient of $1.6 \times 10^{-5} \mathrm{~cm}^{2} / \mathrm{s}, 2.2 \times 10^{-5} \mathrm{~cm}^{2} / \mathrm{s}$ and $3.0 \times 10^{-5} \mathrm{~cm}^{2} / \mathrm{s}$, respectively.

Fig. 7. Indium composition profiles of the $\mathrm{GaSb} / \mathrm{InSb} / \mathrm{GaSb}$ sandwich sample measured by X-ray penetration method. The circular, rectangular and triangular points indicate the indium composition profiles at $1 \mathrm{~h}, 3 \mathrm{~h}$ and $5 \mathrm{~h}$ after loading the sample, respectively.

Fig. 8. The indium composition profile measured by EPMA after the X-ray penetration 
experiment. 